University of Nebraska - Lincoln

DigitalCommons@University of Nebraska - Lincoln

2011

\title{
The impact of endorsing Spitzer's proposed criteria for PTSD in the forthcoming DSM-V on male and female Veterans
}

Lyndsey N. Miller

Department of Mental Health and Substance Abuse

Kathleen M. Chard

Cincinnati Veteran's Administration Medical Center

Jeremiah A. Schumm

Cincinnati Veteran's Administration Medical Center

Carol O'Brien

Bay Pines Veteran's Administration Healthcare System

Follow this and additional works at: https://digitalcommons.unl.edu/publichealthresources

Part of the Public Health Commons

Miller, Lyndsey N.; Chard, Kathleen M.; Schumm, Jeremiah A.; and O’Brien, Carol, "The impact of endorsing Spitzer's proposed criteria for PTSD in the forthcoming DSM-V on male and female Veterans" (2011). Public Health Resources. 186.

https://digitalcommons.unl.edu/publichealthresources/186

This Article is brought to you for free and open access by the Public Health Resources at DigitalCommons@University of Nebraska - Lincoln. It has been accepted for inclusion in Public Health Resources by an authorized administrator of DigitalCommons@University of Nebraska - Lincoln. 


\title{
The impact of endorsing Spitzer's proposed criteria for PTSD in the forthcoming DSM-V on male and female Veterans
}

\author{
Lyndsey N. Miller ${ }^{\mathrm{a}, *}$, Kathleen M. Chard ${ }^{\mathrm{b}}$, Jeremiah A. Schumm ${ }^{\mathrm{b}}$, Carol O’Brien ${ }^{\mathrm{c}}$ \\ a Department of Mental Health and Substance Abuse, 790 Gov. Carlos G. Camacho Road, Tamuning 96913, Guam \\ b Cincinnati Veteran's Administration Medical Center, 3200 Vine Street, Cincinnati, OH 45220, United States \\ ' Bay Pines Veteran's Administration Healthcare System, 10000 Bay Pines Boulevard, Bay Pines, FL 33744, United States
}

\section{A R T I C L E I N F O}

\section{Article history:}

Received 5 June 2010

Received in revised form 12 January 2011

Accepted 14 February 2011

Keywords:

Posttraumatic stress disorder

Veterans

DSM-V

Trauma

\begin{abstract}
A B S T R A C T
This study explored differences between Spitzer's proposed model of posttraumatic stress disorder (PTSD) and the current DSM-IV diagnostic classification scheme in 353 Veterans. The majority of Veterans (89\%) diagnosed with PTSD as specified in the DSM-IV also met Spitzer's proposed criteria. Veterans who met both DSM-IV and Spitzer's proposed criteria had significantly higher Clinician Administered PTSD Scale severity scores than Veterans only meeting DSM-IV criteria. Logistic regression indicated that being African American and having no comorbid diagnosis of major depressive disorder or history of a substance use disorder were found to predict those Veterans who met current, but not proposed criteria. These findings have important implications regarding proposed changes to the diagnostic classification criteria for PTSD in the forthcoming DSM-V.
\end{abstract}

(c) 2011 Elsevier Ltd. All rights reserved.

\section{Introduction}

Since the admission of posttraumatic stress disorder (PTSD) to the diagnostic nomenclature in the third edition of the Diagnostic and Statistical Manual of Mental Disorders (DSM-III; American Psychiatric Association, 1980), researchers have investigated various diagnostic conceptualizations for PTSD (Breslau \& Davis, 1987; Burstow, 2005; McNally, 2004). Ongoing evaluation, and possibly updating, of PTSD criteria is essential in order to reflect current research findings on the etiology, presentation, and diagnosis of PTSD. An accurate understanding and conceptualization of posttraumatic symptoms are fundamental prerequisites to developing effective treatments to decrease, and potentially to protect against psychological distress associated with the effects of trauma.

In anticipation of the upcoming DSM-V, numerous researchers have proposed revised criteria for PTSD (Brewin, Lanius, Novac, Schnyder, \& Galea, 2009; DSM-V Task Force, 2010; Spitzer, First, \& Wakefield, 2007) that more clearly reflect the latest research results. Most recently the DSM-V Task Force (2010) has proposed PTSD diagnostic criteria that includes a broader range of symptoms that may be more inclusive, while other researchers have proposed revised criteria for PTSD that would tighten the PTSD diagnostic classification (Brewin et al., 2009; Spitzer et al., 2007). These later

\footnotetext{
* Corresponding author. Tel.: +671 488 9114; fax: +671 6475402.

E-mail addresses: lyndseynmiller@aol.com (L.N. Miller), Kathleen.Chard@va.gov (K.M. Chard), Jeremiah.Schumm@va.gov (J.A. Schumm), Carol.OBrien1@va.gov (C. O'Brien).
}

proposals are in response to many researchers who argue that the new criteria should be more specific to a unique trauma related syndrome (Bodkin, Pope, Detke, \& Hudson, 2007; Brewin et al., 2009; McNally, 2004).

Many have questioned the specificity of PTSD (Bodkin et al., 2007; Brewin et al., 2009; Green, Lindy, \& Grace, 1985; Lindy, Green, \& Grace, 1987) due to the significant symptom overlap with other disorders, especially Major Depressive Disorder (MDD) and Generalized Anxiety Disorder (GAD). For example, anhedonia, lack of concentration, and problems with sleep as well as irritability are all features of PTSD that are also characteristic of depression (APA, 2000; Fava et al., 2010). In addition, impaired concentration, hyperarousal and sleep difficulty are also characteristic of GAD (APA, 2000). If researchers are correct in their assumption that the symptom overlap decreases the diagnostic specificity of PTSD, then by extension PTSD has likely been lacking specificity since its existence in the psychiatric nomenclature. This hypothesis is not surprising given the significant comorbidity of PTSD, MDD, and GAD. The National Comorbidity Survey (Kessler, Sonnega, Hughes, \& Nelson, 1995 ) estimated nearly $50 \%$ of men and women who had PTSD also had MDD. Other studies have found estimates of comorbid PTSD and MDD as high as 77\% and estimates of PTSD and GAD as high as 38\% (Brown, Campbell, Lehman, Grisham, \& Mancill, 2001). Generally, PTSD demonstrates one of the highest rates of comorbidity among psychiatric disorders (Kessler, Chiu, Demler, \& Walters, 2005).

Regardless of symptom overlap and high comorbidity, many researchers argue that PTSD is unique and distinguishable from MDD (Blanchard, Buckley, Hickling, \& Taylor, 1998) and GAD 
(Keane, Taylor, \& Penk, 1997). Researchers who have examined the impact of these overlapping symptoms on comorbidity in individuals with PTSD have found no difference in comorbid MDD rates (Elhai, Grubaugh, Kashdan, \& Frueh, 2008; Franklin \& Zimmerman, 2001). In addition, Barlow, DiNardo, Vermilyea, Vermilyea, and Blanchard (1986) have argued that symptom overlap among disorders is merely evidence that psychopathology arises from a constitutional predisposition involving many factors and manifests accordingly due to individual and environmental influences. Others, however, continue to debate the issue and insist that the symptom overlap of PTSD and other psychiatric disorders is a fundamental flaw of the diagnosis and confounds the specificity of the syndrome (Bodkin et al., 2007; Breslau \& Davis, 1987).

Spitzer et al. (2007) agreed with many of the assertions suggesting that the current criteria for PTSD are flawed and they proposed the following revisions to the diagnostic classification. Although they suggested changing the stressor criterion and the specifiers of the diagnosis, the most significant modifications were recommended to address the issue of poor specificity. Specifically, they proposed eliminating the symptoms of PTSD that overlap with other disorders, including sleep problems, anhedonia, difficulty concentrating, and irritability, within the avoidance and hyperarousal criteria. Additional suggested changes appeared to be less linked to current criticism and included (1) deleting impaired recall of an important element of the trauma (C3 criterion). The authors did not fully discuss their rationale for this change but they may have been responding to the numerous studies that have found poor correlations between the C 3 criterion and other PTSD symptoms (Buckley, Blanchard, \& Hickling, 1998; King, Leskin, King, \& Weathers, 1998; Simms, Watson, \& Doebbeling, 2002); (2) combining the remaining $C$ and $D$ criteria into a single list rather than two separate criterion categories. The new criterion $C$ would include the following symptoms: (1) efforts to avoid thoughts, feelings, or conversations associated with the trauma, (2) efforts to avoid activities, places, or people that arouse recollections of the trauma, (3) feelings of detachment or estrangement from others, (4) restricted range of affect, (5) sense of a foreshortened future, (6) hypervigilance, and (7) exaggerated startle response; and (3) requiring at least four of the symptoms in this combined group along with the other criteria for the diagnosis to be met.

A review of the literature revealed three studies to date that have examined Spitzer's proposed criteria (Elhai et al., 2008; Ford, Elhai, Ruggiero, \& Frueh, 2009; Grubaugh, Long, Elhai, Frueh, \& Magruder, 2010). Thus far, when Spitzer's proposed criteria were compared to the current DSM-IV criteria, researchers found little or no difference in lifetime PTSD prevalence among adult community (Elhai et al., 2008) and primary care veteran samples (Grubaugh et al., 2010). In contrast, lower rates of lifetime PTSD prevalence were identified when Spitzer's criterion set was employed in a community sample of adolescents (Ford et al., 2009). With regards to psychiatric comorbidity, all three studies revealed no difference when Spitzer's criteria were compared to the current DSM-IV criterion set. However, when Ford et al. (2009) utilized an alternative criteria threshold (three versus four hyperarousal/avoidance symptoms) for Spitzer's model, they found lower rates of comorbid depression in their sample of adolescents. Additionally, lifetime PTSD prevalence rates among the adolescent sample also became comparable to current lifetime rates once the criterion threshold was manipulated. Furthermore, all three studies found Spitzer's two factor model of PTSD to be structurally adequate and superior to the current three factor model. Therefore, the findings examining Spitzer's revised criterion set have been mixed.

The current study extended these previous findings by examining the impact of utilizing Spitzer's proposed criteria on a Veteran population seeking treatment for PTSD. This study identified the proportion of Veterans who met PTSD diagnostic criteria according to both the DSM-IV and Spitzer's proposed criteria as well as those who no longer met diagnostic criteria when Spitzer's criteria were employed. Additionally, this study examined potential predictors for maintaining a diagnosis of PTSD using Spitzer's criteria. Comorbidity of PTSD with MDD, GAD, and substance use disorders was also explored as a potential predictor due to prior research demonstrating high comorbidity of these disorders (Brown et al., 2001; Kessler et al., 2005, 1995). Additionally, individuals with PTSD and other comorbid disorders such as depression and substance abuse have been found to evidence more severe PTSD symptomatology (Back, Sonne, Killeen, Dansky, \& Brady, 2003; Momartin, Silove, Manicavasagar, \& Steel, 2004), and typically have poorer treatment outcomes (Cloitre \& Koenen, 2001). Therefore, PTSD symptom severity was examined as a potential predictor of group membership. Although researchers have found no consistent difference in demographic variables among individuals with PTSD with regards to PTSD symptom severity (Frueh, Brady, \& de Arellano, 1998; Norris, 1992; Pole, Gone, \& Kulkarni, 2008; Roemer, Litz, Orsillo, Ehlich, \& Friedman, 1998; Ullman, Filipas, Townsend, \& Starzynski, 2007), these variables were also investigated as potential predictors of group membership.

\section{Method}

\subsection{Procedure and participants}

Before initiation of the study, approval from appropriate Institutional Review Boards was obtained. Archival data of male and female Veterans from a Midwestern VA Medical Center PTSD and Anxiety Disorders Clinic (PTSD Clinic) was entered into a database and included demographic characteristics and test scores for each veteran. Data was derived from consecutive admissions to the PTSD Clinic from January 2006 to May $2008(n=555)$. Veterans who did not meet either current or proposed criteria $(n=193)$ for PTSD, as measured by the Clinician Administered PTSD Scale (CAPS), were excluded, leaving 362 Veterans that were included in the analyses for this study. As shown in Table 1, 93.1\% were outpatients, $88.7 \%$ were male, and $79.0 \%$ were White. Additionally, $48.6 \%$ of the Veterans were from the Vietnam era, $67.1 \%$ had combat related traumas, $60.8 \%$ had a diagnosis of major depressive disorder (MDD), $40.1 \%$ had a history of a substance use disorder (SUD), and $12.2 \%$ had no other Axis I diagnosis (NODX). Further information on the population and groups examined can be found in Table 1 .

\subsection{Measures}

CAPS (Blake et al., 1990). The CAPS was used to determine diagnostic criteria for both current DSM-IV PTSD criteria and Spitzer's proposed criteria for DSM-V as well as to assess severity of PTSD symptoms. The CAPS is a structured clinical interview that is considered the "gold standard" in assessment of PTSD (Keane, Brief, Pratt, \& Miller, 2007). The CAPS has the unique ability to measure PTSD symptomatology both dichotomously and continuously. Each symptom is rated on both frequency and intensity of occurrence. Symptom criteria are scored on a scale of $0-4$, with 0 representing absence of the symptom and 4 representing the greatest level of severity. Several researchers have examined the different scoring rules for the presence or absence of symptoms using the CAPS to diagnose PTSD (Blanchard et al., 1995; Fleming \& Difede, 1999; Weathers, Ruscio, \& Keane, 1999) and have suggested more lenient scoring rules for screening, while more stringent scoring rules have been suggested for confirming the diagnosis of PTSD. The current study employed the original scoring rule proposed by Blake et al. (1990) which specifies that a frequency of one or more and an intensity of two or more on a symptom constitutes a positive result for 
Table 1

Demographic characteristics.

\begin{tabular}{|c|c|c|c|c|}
\hline Characteristic & Overall $(n=362)$ & Met both $(n=314)$ & Met current only $(n=39)$ & Met proposed only $(n=9)$ \\
\hline Outpatient & $93.1 \%$ & $92.7 \%$ & $94.9 \%$ & $100 \%$ \\
\hline Male & $88.7 \%$ & $88.2 \%$ & $89.7 \%$ & $100 \%$ \\
\hline African American & $14.9 \%$ & $13.4 \%$ & $28.2 \%$ & $11.1 \%$ \\
\hline White & $79.0 \%$ & $80.3 \%$ & $66.7 \%$ & $88.9 \%$ \\
\hline Other race & $5.8 \%$ & $6.7 \%$ & - & - \\
\hline Pre-Vietnam era & $1.4 \%$ & $1.0 \%$ & $5.1 \%$ & - \\
\hline Vietnam era & $48.6 \%$ & $48.7 \%$ & $43.6 \%$ & $66.7 \%$ \\
\hline Persian Gulf era & $12.7 \%$ & $12.7 \%$ & $12.8 \%$ & $11.1 \%$ \\
\hline OEF/OIF era & $25.7 \%$ & $25.8 \%$ & $30.8 \%$ & - \\
\hline Other era & $0.08 \%$ & $0.06 \%$ & - & $11.1 \%$ \\
\hline Combat trauma & $67.1 \%$ & $67.2 \%$ & $64.1 \%$ & $77.8 \%$ \\
\hline MDD & $60.8 \%$ & $64.0 \%$ & $43.6 \%$ & $22.2 \%$ \\
\hline SUD & $42.4 \%$ & $42.4 \%$ & $23.1 \%$ & $33.3 \%$ \\
\hline OTHER & $40.6 \%$ & $41.5 \%$ & $38.5 \%$ & $33.3 \%$ \\
\hline NODX & $10.2 \%$ & $10.2 \%$ & $23.1 \%$ & $33.3 \%$ \\
\hline
\end{tabular}

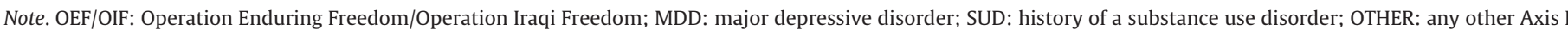
diagnosis, except MDD or SUD; NODX: no diagnosis on Axis I.

that symptom. Although Blake's scoring rule is more lenient than others, it was used for two reasons. First, this scoring rule ensures that all Veterans who are experiencing distress and meet criteria can be treated. Second, this scoring rule was used in order to avoid false negatives and increase true positives.

The CAPS can be administered using either a one week or one month time frame (Blake et al., 1990). Data available for this study was based upon the one week version. This time frame was utilized for the clinical purpose of tracking pre- and post-treatment symptom status related to the course of therapy. However, Veterans were queried on the duration of their PTSD symptoms at the initial assessment to establish PTSD diagnosis. Symptoms lasting less than one month were not diagnosed as PTSD.

Weathers, Keane, and Davidson (2001) reviewed 10 years of research establishing the psychometric properties of the CAPS. Interrater reliability was at or above the .90 level for continuous CAPS scores, while test-retest reliability was similarly high at .93 or above. Internal consistency was also high with alphas ranging from .80 to .90 across symptoms clusters and with all 17 symptoms. Convergent validity was in the .70-.90 range when compared to self-report measures of PTSD. Diagnostic utility evidenced sensitivities and specificities above .80 and kappas above .70 .

SCID-IV (First, Spitzer, Williams, \& Gibbon, 2000). The SCID-IV was used in this study to assess comorbid psychiatric conditions on Axis I. The SCID-IV is a semi-structured interview that corresponds to the DSM-IV diagnostic criteria. The SCID-IV has demonstrated high interrater reliability and adequate reliability in the assessment of a wide range of disorders (Hoffart, Thornes, \& Hedley, 1995; Schlenger et al., 1992; Ventura, Liberman, Green, Shaner, \& Mintz, 1998). For this study, the authors only reviewed veteran's results on the Depression, Anxiety, and Substance Use modules as well as the screening module for Psychotic Disorders.

\section{Results}

\subsection{Diagnostic frequencies}

Frequency counts were conducted to determine how many participants met both current and proposed criteria (BOTH), only current criteria (CRT), or only proposed criteria for PTSD (PROP). A total of 314 Veterans were in the BOTH group, 39 Veterans were in the CRT group, and 9 Veterans were in the PROP group. The majority (89\%) of Veterans who met the current criteria for PTSD also met Spitzer's proposed criteria. Interestingly, $2 \%(n=9)$ of the Veterans examined who did not meet the current criteria for PTSD in DSMIV, met the proposed criteria for PTSD. This group was excluded from further analyses due to the small number of Veterans in the group.

\subsection{Demographic comparisons between groups}

Next, demographic differences between the BOTH and CRT groups were compared. Omitted demographic data were excluded from the respective analyses. There was a significant difference in educational level between the BOTH $(M=12.94, S D=1.97)$ and CRT group $(M=13.89, S D=2.20), t(327)=-2.70, p<.05$; however, the effect size $(d=0.009)$ indicated that although education was statistically different, the magnitude of the difference between education levels was not practically relevant. There was no difference found between the BOTH and CRT groups with regards to age, gender, or service era.

Examination of race indicated that African American Veterans were more likely to be in the CRT group than in the BOTH group, $\chi^{2}$ $(n=331,1)=5.83, p=.02, \varphi=0.13$. An additional analysis was completed to determine if there was a difference between race and PTSD symptom severity in the overall sample. The BOTH group was comprised of $86 \%$ White Veterans versus $14 \%$ African American Veterans, while the CRT group was comprised of $70 \%$ White Veterans versus 30\% African American Veterans. The two groups did not meet the assumption of equal variance; therefore, $t$-test comparisons were based on the assumption that variances were not equal between the two groups. Individual sample $t$-test indicated that there was no difference between African Americans and Whites in PTSD symptom severity in the overall sample. Veterans identified as Hispanic/Latino, other, or another multicultural group were excluded in the final analysis of race due to small size $(n=9)$.

\subsection{PTSD severity comparisons between groups}

The individual symptom clusters (B, C, and D criteria) and overall total CAPS scores of the BOTH and CRT groups were then examined to compare PTSD symptom severity. Individual sample $t$-tests were employed to compare symptom severity between the BOTH and CRT groups across the symptom clusters and overall totals. The BOTH group's total reexperiencing (criteria B), avoidance (criteria C), and hyperarousal (criteria D) symptom severity cluster totals were all significantly higher than the CRT group (see Table 2). Additionally, the BOTH group's overall total symptom severity score on the CAPS was significantly higher than the CRT group.

CAPS scores examining only Spitzer's criteria were also compared. Individual sample $t$-tests were employed to compare the BOTH and CRT groups across the symptom clusters (B, C, and D cri- 
Table 2

CAPS scores comparison between Veterans who met both DSM-IV-TR and Spitzer's proposed criteria for PTSD versus Veterans who only met current DSM-IV-TR criteria.

\begin{tabular}{|c|c|c|c|c|c|}
\hline & Meets both $(n=314) M(S D)$ & Meets current only $(n=39) M(S D)$ & $t$ & $p$ & Cohen's $d$ \\
\hline \multicolumn{6}{|l|}{ DSM-IV-TR } \\
\hline B total & $19.0(6.9)$ & $14.1(5.4)$ & 4.23 & $<.001$ & 0.45 \\
\hline C total & $29.4(8.1)$ & $19.8(5.3)$ & 10.02 & $<.001$ & 2.53 \\
\hline D total & $24.0(5.7)$ & $18.0(5.5)$ & 6.26 & $<.001$ & 0.67 \\
\hline $\begin{array}{l}\text { Overall total } \\
\text { Spitzer proposed }\end{array}$ & $72.5(15.9)$ & $51.9(10.1)$ & 11.11 & $<.001$ & 2.77 \\
\hline Overall total & $50.8(12.1)$ & $31.5(8.0)$ & 13.3 & $<.001$ & 3.38 \\
\hline
\end{tabular}

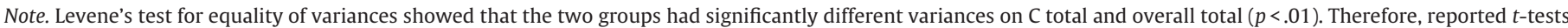
for $\mathrm{C}$ total and overall total scores are based upon corrections that do not assume equal variances.

teria) and overall total with only Spitzer's proposed criteria. The BOTH group had significantly higher total overall CAPS scores on the 12 symptoms when compared to the CRT group (see Table 2 ).

\subsection{Psychiatric comorbidity comparisons between groups}

Next, differences in psychiatric comorbidity between the BOTH and CRT group were explored. Omitted diagnostic data were excluded from the respective analyses. The data indicated that Veterans in the BOTH group were more likely to have a diagnosis of MDD than Veterans in the CRT group, $\chi^{2}(n=353,1)=6.13$, $d f=1, p=.01, \varphi=0.13$. Sixty-four percent of Veterans in the BOTH group also met criteria for depression versus only $44 \%$ in the CRT group. Next, Veterans in the BOTH group were more likely to have SUD than Veterans in the CRT group, $\chi^{2}(n=353,1)=5.36, p=.02$, $\varphi=0.12$. Forty-two percent of Veterans in the BOTH group reported SUD versus only $23 \%$ in the CRT group. Additionally, Veterans in the CRT group were more likely to have NODX than Veterans in the BOTH group, $\chi^{2}(n=353,1)=5.61, p=.02, \varphi=0.13$. Twenty-three percent of Veterans in the CRT group had no other Axis I diagnosis versus $10 \%$ of Veterans in the BOTH group. Finally, other comorbid diagnoses were examined, with particular interest in comorbid anxiety disorders. Analyses of all other Axis I disorders examined indicated no differences between the BOTH and CRT groups.

\subsection{Predictions of group membership}

Variables that significantly differentiated the CRT from BOTH groups in bivariate analyses were entered into a multivariate logistic regression that included CRT versus BOTH as the outcome variable. The odds ratio (OR) and 95\% confidence intervals (CIs) for each variable in the analysis are presented in Table 3 . In the final model, African Americans were over 30\% more likely to be in the CRT group than Whites. Veterans with a diagnosis of MDD were almost $45 \%$ more likely to be in the BOTH group than those without MDD. Likewise, Veterans with SUD were $40 \%$ more likely to be in the BOTH group than Veterans without SUD. Education was not significantly related to BOTH versus CRT group membership.

\section{Discussion}

The results of this study showed that the majority of Veterans (89\%) who met criteria for PTSD in DSM-IV also met Spitzer's proposed criteria. In the overall sample there was no difference between African Americans and Whites in PTSD symptom severity. However, African America race, less psychiatric comorbidity of MDD and SUD, and less severe PTSD symptomatology predicted Veterans who met DSM-IV PTSD criteria, but not Spitzer's proposed PTSD criteria. Additionally, although a significant difference was found for education in the CRT versus BOTH group in bivariate comparisons, results suggested that this difference is probably accounted for by other variables, including race and psychiatric comorbidity.

In contrast to previous studies examining Spitzer's proposed PTSD criteria that found no difference in psychiatric comorbidity when comparing individuals who met both current and proposed PTSD criteria and those who only met current (Elhai et al., 2008; Ford et al., 2009; Grubaugh et al., 2010), the current study found greater comorbity of substance use disorders and MDD among the group that met both PTSD criteria. Additionally, the group that met both criteria evidenced greater PTSD symptom severity. These findings are consistent with research that has shown a relationship between PTSD symptom severity and comorbid depression and substance abuse (Back et al., 2003; Momartin et al., 2004). Thus, Spitzer's revised criterion set may have identified those individuals who manifested greater psychopathology in response to psychological trauma.

In addition to these findings, White Veterans in this study appeared to endorse fewer of the PTSD symptoms that overlap with other disorders-the symptoms Spitzer et al. proposed deleting-and had a greater likelihood of meeting the proposed criteria. These results indicate that the manifestation of traumarelated symptomatology may be different in White Veterans as compared to African American Veterans. Thus, if Spitzer's criteria are endorsed, some groups of Veterans, including those who are African American, might be less likely to be diagnosed with PTSD. Instead the distress reactions of these Veterans may be more susceptible to classification as a mood disorder, such as major depression. In this case, it is possible that Veterans who meet the current, but not Spitzer's proposed criteria would be more likely to receive mood- rather than PTSD-focused interventions. This suggests a clear need for research to better understand whether mood-focused interventions are efficacious for treating veterans with lower severity PTSD who do not meet criteria for Spitzer's proposed diagnostic revision for PTSD. These findings also suggest a need to better understand factors that may underlie differences in veterans' post-traumatic psychological distress reactions across ethnic groups.

Table 3

Multivariate regression predicting outcome, with BOTH group as referent category.

\begin{tabular}{|c|c|c|c|c|}
\hline Variable & Beta & $p$ & OR & $95 \%$ confidence interval \\
\hline RACE & 1.15 & .009 & 0.32 & $0.13-0.75$ \\
\hline EDUCATION & 0.15 & .088 & 1.16 & $0.98-1.38$ \\
\hline MDD & -0.82 & .030 & 0.44 & $0.21-0.92$ \\
\hline SUD & -0.92 & .039 & 0.40 & $0.17-0.96$ \\
\hline
\end{tabular}

Note. Race (African American =0; White =1); MDD: major depressive disorder; SUD: history of a substance use disorder. 


\subsection{Limitations and recommendations for future research}

There were several limitations to this study that should be addressed in future research. First, the results of this study may not be generalizable to other populations due to this study's focus on Veterans, the majority of which were males who experienced combat related traumas. Additionally, differences in trauma severity and the impact of experiencing multiple traumas on group membership or symptom severity were not examined. Future research should examine the proposed criteria with a variety of traumas and levels of symptom severity to determine any differences.

In addition, this study examined only one set of proposed PTSD diagnostic criteria. Recent documents released by the DSM-V PTSD Task Force (2010) suggest that they may be moving in the opposite direction of Spitzer, with more of a focus on broadening, rather than tightening, the definition of PTSD. Specifically, the Task Force proposes adding maladaptive cognitive changes as symptoms of PTSD, while also adopting a four factor solution to the criterion set, rather than the current three factor model. Many researchers have identified flaws to the fundamental three factor solution of the current DSM-IV PTSD criteria and favor two or four factor solutions (Amdur \& Liberzon, 2001; Asmundson et al., 2000; Buckley et al., 1998; King et al., 1998; Simms et al., 2002; Smith, Redd, DuHamel, Vicksberg, \& Ricketts, 1999; Taylor, Kuch, Koch, Crockett, \& Passey, 1998). Future research examining the Task Force's revised criterion set with deletion of overlapping symptoms as proposed by Spitzer is recommended in addition to evaluation of other alternative diagnostic classifications. Accordingly, these investigations will also reveal potential treatment implications of adopting a new diagnostic system for PTSD.

\subsection{Conclusions}

Spitzer et al. (2007) intended to improve the diagnostic criteria for PTSD by proposing several changes to the criteria for PTSD in the forthcoming DSM-V. The results of this study indicated that Spitzer's proposed changes may indeed make the diagnosis more specific to unique PTSD symptomatology. Our findings suggest that if Spitzer's proposed changes to PTSD criteria in the DSM-V are endorsed, the new criteria will include most of the Veterans who are already diagnosed with PTSD (89\% in this sample). However, more than $10 \%$ of Veterans will no longer meet the diagnostic criteria for PTSD. Based on this study, the new criteria may identify Veterans with more severe psychopathology and those with less severe symptomatology who no longer meet the diagnostic criteria will no longer be labeled as having PTSD. Although these Veterans may be experiencing less severe symptomatology, treatment may still be important to address significant functional impairments. Further research evaluating alternative diagnostic conceptualizations and resultant treatment implications is essential to our ability to develop and implement effective treatments for those who have experienced psychological trauma.

\section{References}

Amdur, R. L., \& Liberzon, I. (2001). The structure of posttraumatic stress disorder symptoms in combat veterans: a confirmatory factor analysis of the Impact of Event Scale. Journal of Anxiety Disorders, 15(4), 345-357.

American Psychiatric Association. (1980). Diagnostic and statistical manual of mental disorders (3rd ed.). Washington, DC: American Psychiatric Association.

American Psychiatric Association. (2000). Diagnostic and statistical manual of mental disorders (4th ed. rev.). Washington, DC: American Psychiatric Association.

Asmundson, G. J. G., Frombach, I., McQuaid, J., Pedrelli, P., Lenox, R., \& Stein, M. B. (2000). Dimensionality of posttraumatic stress symptoms: a confirmatory analysis of DSM-IV symptom clusters and other symptom models. Behaviour Research and Therapy, 38, 203-214.

Back, S. E., Sonne, S. C., Killeen, T., Dansky, B. S., \& Brady, K. T. (2003). Comparative profiles of women with PTSD and comorbid cocaine or alcohol dependence. American Journal of Drug and Alcohol Abuse, 29, 169-189.
Barlow, D. H., DiNardo, P. A., Vermilyea, B. B., Vermilyea, J., \& Blanchard, E. B. (1986). Co-morbidity and depression among the anxiety disorders. The Journal of Nervous and Mental Disease, 174(2), 63-72.

Blake, D. D., Weathers, F. W., Nagy, L. M., Kaloupek, D. G., Klauminizer, G., Charney, D. S., et al. (1990). A clinical rating scale for assessing current and lifetime PTSD: the CAPS-1. Behavior Therapist, 18, 187-188.

Blanchard, E. B., Buckley, T. C., Hickling, E. J., \& Taylor, A. E. (1998). Posttraumatic stress disorder and comorbid major depression: is the correlation an illusion? Journal of Anxiety Disorders, 12(1), 21-37.

Blanchard, E. B., Hickling, E. J., Taylor, A. E., Forneris, C. A., Loos, W. R., \& Jaccard, J. (1995). Effects of varying scoring rules of the Clinician-Administered PTSD Scale (CAPS) for the diagnosis of post-traumatic stress disorder in motor vehicle accidents victims. Behavioral Research Therapy, 33, 471-475.

Bodkin, J. A., Pope, H. G., Detke, M. J., \& Hudson, J. I. (2007). Is PTSD caused by traumatic stress? Journal of Anxiety Disorders, 21(2), 176-182.

Breslau, N., \& Davis, G. C. (1987). Posttraumatic stress disorder: the stressor criterion. Journal of Nervous and Mental Disease, 175(5), 255-264.

Brewin, C. R., Lanius, R. A., Novac, A., Schnyder, U., \& Galea, S. (2009). Reformulating PTSD for DSM-V: life after criterion A. Journal of Traumatic Stress, 22(5.), 366-373.

Brown, T. A., Campbell, L. A., Lehman, C. L., Grisham, J. R., \& Mancill, R. B. (2001). Current and lifetime comorbidity of the DSM-IV anxiety and mood disorder in a large clinical sample. Journal of Abnormal Psychology, 110(4), 585-599.

Buckley, T. C., Blanchard, E. B., \& Hickling, E. J. (1998). A confirmatory factor analysis of posttraumatic stress symptoms. Behaviour Research and Therapy, 36, 1091-1099.

Burstow, B. (2005). A critique of posttraumatic stress disorder and the DSM. Journal of Humanistic Psychology, 45(4), 429-445.

Cloitre, M., \& Koenen, K. C. (2001). The impact of borderline personality disorder on process group outcome among women with posttraumatic stress disorder related to childhood abuse. International Journal of Group Psychotherapy, 51, 379-398.

DSM-V Task Force. (2010). DSM-V: the future of psychiatric diagnosis: posttraumatic stress disorder. Retrieved from http://www.dsm5.org/ ProposedRevisions/Pages/proposedrevision.aspx?rid=165.

Elhai, J. D., Grubaugh, A. L., Kashdan, T. B., \& Frueh, B. C. (2008). Empirical examination of a proposed refinement to DSM-IV posttraumatic stress disorder symptom criteria using the national comorbidity survey replication data.Journal of Clinical Psychiatry, 69(4), 597-602.

Fava, M., Hwang, I., Rush, A. J., Sampson, N., Walters, E. E., \& Kessler, R. C. (2010). The importance of irritability as a symptom of major depressive disorder: results from the National Comorbidity Survey Replication. Molecular Psychiatry, 15(8), 856-867.

Fleming, M. P., \& Difede, J. (1999). Effects of varying scoring rules of the Clinician Administered PTSD Scale (CAPS) for the diagnosis of PTSD after acute burn injury. Journal of Traumatic Stress, 12, 535-542.

First, M., Spitzer, R., Williams, J., \& Gibbon, M. (2000). Structured clinical interview for DSM-IV Axis I Disorders (SCID-I). In: American Psychiatric Association (Ed.), Handbook of psychiatric measures (pp. 49-53). Washington, DC: American Psychiatric Association.

Ford, J. D., Elhai, J. D., Ruggiero, K. J., \& Frueh, B. C. (2009). Refining the posttraumatic stress disorder diagnosis: evaluation of symptom criteria with the National Survey of Adolescents. Journal of Clinical Psychiatry, 70(5), 748-755.

Franklin, C. L., \& Zimmerman, M. (2001). Posttraumatic stress disorder and major depressive disorder: investigating the role of overlapping symptoms in diagnostic comorbidity. Journal of Nervous and Mental Disease, 189(8), 548-551.

Frueh, B. C., Brady, K. L., \& de Arellano, M. A. (1998). Racial differences in combatrelated PTSD: empirical findings and conceptual issues. Clinical Psychology Review, 18(3), 287-305.

Green, B. L., Lindy, J. D., \& Grace, M. C. (1985). Posttraumatic stress disorder: toward DSM-IV. Journal of Nervous and Mental Disease, 173(7), 406-411.

Grubaugh, A. L., Long, M. E., Elhai, J. D., Frueh, B. C., \& Magruder, K. M. (2010). An examination of the construct validity of posttraumatic stress disorder with veterans using a revised criterion set. Behaviour Research and Therapy, 48, 909-914.

Hoffart, A., Thornes, K., \& Hedley, L. V. (1995). DSM-III-R Axis I and II disorders in agoraphobic inpatients with and without panic disorder before and after psychosocial treatment. Psychiatry Research, 56(1), 1-9.

Keane, T. M., Brief, D. J., Pratt, E. M., \& Miller, M. W. (2007). Assessment of PTSD and its comorbidities in adults. In: M. J. Friedman, T. M. Keane, \& P. A. Resick (Eds.), Handbook of PTSD: science and practice (pp. 279-305). New York: Guilford Press.

Keane, T. M., Taylor, K. L., \& Penk, W. E. (1997). Differentiating post-traumatic stress disorder (PTSD) from major depression (MDD) and generalized anxiety disorder (GAD). Journal of Anxiety Disorders, 11(3), 317-328.

Kessler, R. C., Chiu, W. T., Demler, O., \& Walters, M. S. (2005). Prevalence, severity, and comorbidity of 12-month DSM-IV disorders in the national comorbidity survey replication. Archives of General Psychiatry, 62, 617-627.

Kessler, R. C., Sonnega, A., Hughes, M., \& Nelson, C. B. (1995). Posttraumatic stress disorder in the National Comorbidity Survey. Archives of General Psychiatry, 52, 1048-1060.

King, D. W., Leskin, G. A., King, L. A., \& Weathers, F. W. (1998). Confirmatory factor analysis of the clinician-administered PTSD scale: evidence for the dimensionality of posttraumatic stress disorder. Psychological Assessment, 10, 90-96.

Lindy, J. D., Green, B. L., \& Grace, M. C. (1987). The stressor criterion and posttraumatic stress disorder. Journal of Nervous and Mental Disease, 175(5), 269-272.

McNally, R. J. (2004). Conceptual problems with the DSM-IV criteria for posttraumatic stress disorder. New York, NY, USA: John Wiley \& Sons Ltd. 
Momartin, S., Silove, D., Manicavasagar, V., \& Steel, Z. (2004). Comorbidity of PTSD and depression: associations with trauma exposure, symptom severity and functional impairment in Bosnian refugees resettled in Australia. Journal of Affective Disorders, 80(2-3), 231-238.

Norris, F. (1992). Epidemiology of trauma: frequency and impact of different potentially traumatic events on different demographic groups. Journal of Consulting and Clinical Psychology, 60, 409-418.

Pole, N, Gone, J. P., \& Kulkarni, M. (2008). Posttraumatic stress disorder among ethnoracial minorities in the United States. Clinical Psychology: Science and Practice, $15,35-61$.

Roemer, L., Litz, B. T., Orsillo, S. M., Ehlich, P. J., \& Friedman, M. J. (1998). Increases in retrospective accounts of war-zone exposure over time: the role of PTSD symptom severity. Journal of Traumatic Stress, 11(3), 597-605.

Schlenger, W. E., Kulka, R. A., Fairbank, J. A., Hough, R. L., Jordan, B. K., Marmar, C. R., et al. (1992). The prevalence of lifetime and partial post-traumatic stress disorder in Vietnam theater Veterans. Journal of Traumatic Stress, 5(3), 365-376.

Simms, L. J., Watson, D., \& Doebbeling, B. N. (2002). Confirmatory factor analyses of posttraumatic stress symptoms in deployed and nondeployed Veterans of the Gulf War. Journal of Abnormal Psychology, 111, 637-647.
Smith, M. Y., Redd, W., DuHamel, K., Vicksberg, S. J., \& Ricketts, P. (1999). Validation of the PTSD Checklist - civilian version in survivors of bone marrow transplantation. Journal of Traumatic Stress, 12, 485-499.

Spitzer, R. L., First, M. B., \& Wakefield, J. C. (2007). Saving PTSD from itself in DSM-V. Journal of Anxiety Disorders, 21(2), 233-241.

Taylor, S., Kuch, K., Koch, W. J., Crockett, D. J., \& Passey, G. (1998). The structure of posttraumatic stress symptoms. Journal of Abnormal Psychology, 107(1), 154-160.

Ullman, S. E., Filipas, H. H., Townsend, S. M., \& Starzynski, L. L. (2007). Psychosocial correlates of PTSD symptom severity in sexual assault survivors. Journal of Traumatic Stress, 20(5), 821-831.

Ventura, J., Liberman, R. P., Green, M. F., Shaner, A., \& Mintz, A. (1998). Training and quality assurance with Structured Clinical Interview for DSM-IV (SCID-I/P) Psychiatry Research, 79(2), 163-173.

Weathers, F. W., Keane, T. M., \& Davidson, J. R. T. (2001). Clinician-administered PTSD scale: a review of the first ten years of research. Depression and Anxiety, 13 132-156.

Weathers, F. W., Ruscio, A. M., \& Keane, T. M. (1999). Psychometric properties of nine scoring rules for the Clinician-Administered Post-Traumatic Stress Disorder Scale. Psychological Assessment, 11, 123-133. 